\title{
OS EMBATES ENTRE PSICANÁLISE E MEDICINA NA INSTITUIÇÃO MÉDICA
}

\author{
Renata Petri
}

$U_{\text {ste trabalho é o resultado de }}$ uma reflexão feita sobre o lugar da psicanálise na instituiçào médica, a partir da experiência de um ano de estágio no Serviço de Higiene Mental do Instituto da Criança do Hospital das Clínicas da Universidade de Sào Paulo, serviço este formado basicamente por psicólogos e psiquiatras, a maioria com formaçào analítica.

O título deste artigo sugere um choque impetuoso entre estas duas disciplinas dentro do hospital, lugar por excelência do discurso médico. No entanto esta é uma instituiçào que de alguma maneira, com todas as resistências, permitiu a entrada da psicanálise. Mas que lugar é este? Sabemos que o diálogo entre a psicanálise e a medicina é inexistente, uma vez que são disciplinas com objetos diferentes, e sobretudo com discursos diferentes, opostos, apesalr de muitas vezes conviverem numa mesma instituiçào. Como pensar, entào, dentro da instituiçào mé- dica, qual pode ser o lugar da psicanálise? Vou abordar neste trabalho um lugar possivel que é acolher uma demanda que pode ser formulada a partir de um encaminhamento médico, e uma análise pode se colocar em curso. Neste caso os discursos coabitam em um mesmo espaço, mas nào se interrogam diretamente. Outro lugar possivel para a psicanálise é o questionamento do saber médico, tentando provocar uma báscula, revelá-lo como não-todo, tarefa muito mais árdua. Vou percorrer o caminho dentro da instituição que é realizado por um paciente até chegar eventualmente ao encontro com o analista.

O médico recebe um paciente que chega com uma série de manifestaçôes somáticas. Através de seu olhar clínico observa este corpo que se apresenta e, sem hesitar, receita uma série de exames para aprofundar ainda mais este olhar, até o invisivel. Com os resultados em màos, encontra a denominaçào para

Psicanalista; membro da equipe da Pré-Escola Terapêutica Lugar de Vida, mestranda em Psicologia pela Universidade de São Paulo. 
este estado, chegando ao chamado diagnóstico. O corpo para o médico é o lugar privilegiado onde a doença, seu objeto, localizase. Sendo assim, o que o corpo apresenta tem muito mais valor do que a própria fala do paciente.

Dentro do discurso médico, não há lugar para o sujeito do inconsciente, este perde seu estatuto e passa para a categoria de paciente, ou seja, uma somatória de homem + doença.

Esta categoria não the confere nenhuma possibilidade de fazer interpretaçoes subjetivas sobre o que acomete seu corpo, uma vez que o estado mórbido the retira a capacidade de raciocínio, única maneira possivel de entendimento dentro do discurso médico. O próprio médico, enquanto representante deste saber, deixa sua subjetividade ao largo de seus atos médicos.

Após uma investigaçào minuciosa, alguns casos nào levam a nenhuma etiologia orgânica da doença, nada no corpo é visto ou localizado que a justifique, o paciente nào tem nada - que se encaixe no discurso médico. Nestes casos, sempre dentro do mesmo discurso, considera-se que possa existir um fator psíquico causando esta desorganização orgânica. Estes são os casos que podem ser encaminhados aos profissionais do serviço de Higiene Mental. Os médicos ácreditam que ali se pode detectar qual é o distúrbio e o que deve ser feito para corrigi-lo, embora nào saibam exatamente como se faria isto. Quando o médico faz este encaminhamento, nào é ao analista portador de um outro discurso que o faz, mas aos psicólogos ou psiquiatras do serviço. Estes profissionais entenderiam de uma outra parte de ser humano, o psíquico, como se fosse uma especialidade médica, com os mesmos objetivos e referenciais.

Este paciente pode chegar então ao consultório do psicanalista dentro dos muros da instituição. O que isto acarreta de pronto? Mudança de discurso. E no discurso analítico o sujeito recupera seu posto e seu saber que the tinham sido negados pelo médico.

Comecemos pela própria definiçào de sintoma. O sintoma médico é um sinal ou conjunto de sinais que indicam alguma coisa, levam à etiologia da doença, chegando a um diagnóstico. A partir daí, a conduta médica é de atacar o sintoma para eliminá-lo. Já o sintoma para a psicanálise é uma formação inconsciente, que revela a verdade do sujeito de forma enigmática. "A verdade surpreende o saber que o sujeito crê possuir, dando ao sintoma essa característica que Lacan qualifica assim: é 'o que claudica' (Matet, 1993). O analista nào luta contra o sintoma, escuta-() como qualquer outra formaçào inconsciente, deixando para o paciente a tarefa de construir um saber.

Lacan particulariza o sintoma na criança como uma resposta ao que haveria de sintomático na estrutura familiar, podendo representar a verdade do casal parental. O corpo da criança é capturado pela rede significante e responde a ela. Neste trabalho, sào estas respostas - entendidas como manifestaçòes somáticas carac- 
terizadas por disfunçòes orgânicas sem lesào ou doença crônica que nos interessam para reflexào.

Convém lembrar que me refiro a uma prática analítica dentro de uma instituição médica. Isto quer dizer que o discurso predominante que circula neste espaço é o discurso médico, que tem o sintoma como um significante muito importante e com sentido totalmente diverso daquele do discurso analítico. Às vezes nos deparamos com um mesmo sintoma "dor nos membros" e a cadeia significante desliza de maneira oposta, pois o significante sintoma entra em dois discursos opostos: o médico e o analítico.

Uma outra decorrência que é interessante levantar é a noção de gozo, que nào cabe no discurso médico. O sujeito goza com o seu sintoma, que poderíamos traduzir como um tipo de satisfaçào, ainda que paradoxal: "O sintoma indica que há alguma coisa nào funcionando no campo do real, enquanto o neurótico encontra seu gozo no sintoma, por menos satisfatório que ele seja (...). O sintoma constitui portanto esta anomalia no campo do real em que consiste o gozo. Essa relação ao gozo, o homem dela se queixa, mas não a reconhece." (Matet, 1993).

Nesta medida, fica claro que o desvencilhar-se de um sintoma implica uma renúncia a esse gozo, o que torna essa operação muito mais complexa do que a boa vontade do paciente em seguir as prescriçòes médicas.

A única fórmula que o médico conhece para o significante gozo seria: gozar de boa saúde. Citando Clavreul (1983): "É, portanto, legítimo, se nào sempre com discernimento, que a medicina desconfie do desejo e da procura do prazer. Esta procura é um caminho que conduz à morte, mesmo se não diretamente." A ordem do desejo se contrapòe à ordem médica.

A demanda é um outro ponto importante no tocante às diferenças do referencial médico e analítico. Para o médico ela nào é importante, ou é mesmo desnecessária. Ele passa a tratar, por exemplo, a obesidade de um paciente que o procura por outros motivos. Para o analista a demanda é condiçào para o trabalho, algum pedido deve ser dirigido ao analista. Nos encaminhamentos realizados dentro do hospital, uma porcentagem significativa aparece para uma primeira entrevista, como se fosse realizar mais um exame receitado pelo médico, e como não há nem um esboço de demanda, acabam nào voltando mais.

O lugar que o paciente coloca, de início, tanto o médico como o analista é o mesmo: o de quem tem a verdade sobre seu sintoma. O médico, como representante do saber médico, responde deste lugar com todo o seu saber acumulado sobre o corpo humano. $O$ analista faz, neste lugar, papel de morto, e é o saber do paciente sobre sua verdade que poderá advir.

Fica, então, uma questào: o que leva estes pacientes com sintomas de manifestaçòes somáticas, disfunções, sem eliologia 
orgânica, a insistir em procurar o médico e não o analista, ou o analista só em último caso?

Existiriam dois fatores de ordens diferentes que deteminariam esta questào. Primeiro, a própria condição humana neurótica, que Clavreul (1983) caracteriza muito bem - "a organização neurótica suporta a dor com um masoquismo que nào desmente a queixa do interessado e a afirmação de que ele nào aspira senão a uma vida melhor que a que lhe é imposta. Conforta-se com o espetáculo de sua dor mais facilmente, se não mais felizmente, que com as ambigüidades do discurso que pode sustentar a partir de sua posição subjetiva".

O segundo ponto seria a Ordem Médica, que traduziu sofrimento em dor, e quem tem dor procura o médico. Isto se torna lei a partir do momento em que o discurso médico é o que prevalece na nossa sociedade, ou o discurso científico em geral. É a ciência que detém o saber e a verdade sobre todas as coisas; e a medicina, enquanto uma disciplina dentro da ciência, se destaca por abordar questoes de vida e morte do homem. Foucault(1979), quando percorre os caminhos dos saberes, se depara com o poder que está implicado em qualquer tipo de saber.

Com relaçào ao saber médico, este poder incide sobre o corpo do doente, controlando-o e dominando-o. Citando ainda uma vez Clavreul (1983), "Em nome do princípio de que o saber está no médico e a ignorância no doente, ele se acha justificado para decidir enquanto mestre absoluto, não podendo ninguém duvidar de que ele sabe melhor que qualquer outro qual é o bem de seu doente e de que ele não pode nào desejar este bem". A relação de poder que se instaura numa consulta médica nào está relacionada somente com a natureza dos saberes, mas tam- bém com as diferenças de situação social, passando pelas características da instituição dentro da qual se dá a relação.

Chauí afirma que a ficção científica é a mitologia do século XX. Podemos generalizar esta colocaçào para a ciência de modo geral. Ela tudo explica, ou explicará numa questào de tempo, e dela não é permitido duvidar. No tocante à medicina, esta condição parece chegar, em casos extremos, até as últimas conseqüências, podendo-se realizar verdadeiras atrocidades em nome da ciência.

\section{UM CASO}

- Vou relatar um caso de uma criança e sua mãe, que procuram o médico para responder sobre a verdade de seus sintomas, mas topam reverter este jogo quando lhes é proposto um encontro com um analista.

Na época, Daniela tinha 7 anos e 8 meses e fazia seguimento no serviço de Ambulatório Geral do Instituto da Criança havia quatro anos, apresentando um arsenal de sintomas como: febres, vômitos recorrentes, enurese primária, dor abdominal, cefaléia, artrite migratória, obesidade, encoprese e dificuldade escolar.

Como os exames que tentavam detectar a causa destes sintomas apresentavam resultados sempre negativos, a médica que atendia o caso levou-o para discussão com profissional da Higiene Mental e, entào, essa criança foi encaminhada. Nas entrevistas preliminares, algumas realizadas só com a màe, esta contou a história de Daniela e a sua também. Logo na primeira entrevista, pediu ajuda para fazer sua filha parar de comer e fazer xixi na cama, pois ela nào conseguia ter sucesso na implantaçào destas regras. 
A mãe contou que havia feito uma espécie de promessa quando estava grávida de Daniela: se fosse mulher, não cortaria os cabelos da criança. Por outro lado, não acreditava poder gerar uma filha, pois todas as mulheres de sua família haviam tido somente filhos homens. Ao falar do nascimento desta filha, emocionou-se muito, dizendo que queria dar de tudo para ela. Daniela tem dois irmãos, um de 5 e outro de 11 anos.

A respeito da obesidade a mãe contou que também era gorda quando pequena, na adolescência emagreceu e depois dos filhos voltou a engordar. Num outro momento fez uma aproximação entre os significantes gorda e bonita. Começou dizendo que fazia barra no shorts de seu filho mais velho para aparecer mais a coxa, acha bonito pernas grossas. "Mas a Daniela está bonita demais, bonita exagerada", e explicando melhor, continuou: "gorda demais, precisa emagrecer".

Quando questionada sobre a enurese, a mãe relatou que naquele dia mesmo Daniela não tinha feito xixi na cama porque ela havia lhe prometido uma calça que ela queria (Daniela usava a calça naquela entrevista). Lembrou-se também de uma outra vez que ameaçara castigá-la e novamente conseguiu se controlar. Este sintoma começou, então, a causar enigma na mãe - então existiria um desejo implicado nele, ou ainda, seria preciso mais firmeza para tratar a questão? A mãe foi enurética até os 18 anos, parando depois do casamento.

Disse ainda que, se a menina "puxasse" a mãe ia ser "burrinha mesmo", referindo-se às dificuldades escolares. A màe havia parado de estudar no terceiro ano primário, e dizia que até entào era desligada e nào aprendia algumas coisas.

A mãe relatou então a sua 
história, ficando clara a forte identificaçào que Daniela tinha com ela, respondendo de maneira direta a seu desejo. A mãe fora criada por uma tia, irmã do pai. Seus pais verdadeiros, por uma série de problemas, resolveram pôr os filhos mais velhos no colégio interno e deram-na para esta tia. Quando seu pai verdadeiro morreu, ela ficou sabendo de toda a verdade. Ela é considerada pelos irmãos verdadeiros como privilegiada, viveu mais perto do pai verdadeiro e teve mais mordomias. O que demonstrou, no entanto, foi muita mágoa e raiva desta màe que a criou; nào a pegava no colo, diferentemente do que fazia com os outros filhos, e nunca the dera nada com exceção de um chinelo. Num outro momento lembrou-se que, quando era pequena, tinha os cabelos compridos, dos quais gostava muito e, como uma represália, sua mãe (tia) os cortara bem curtos.

Esta màe tentou resgatar muitas coisas de sua historia através desta filha mulher. Neste movimento, elas se entrelaçaram a ponto de o desejo da màe estar diretamente implicado nos sintomas da criança, e elas viverem uma identificaço que parecia sufocar a criança. Uma situação que ilustra isto muito bem é a promessa que fez de nào cortar os cabelos de sua filha, como se quisesse salvá-la de uma castraçâo que viveu intensamente no real. A màe viveu uma história de violência e privaçào com "suas mães" e parecia nào querer ocupar este lugar na relaça com sua filha, atingindo o outro extremo, nào conseguindo efetuar nenhum corte.

O pai veio a uma única entrevista e se colocou totalmente fora desta relação, dizendo que "a màe deve se ocupar dos filhos, eu trabalho para sustentá-los". Esta postura do pai favorece este colamento de màe e filha, uma vez que nào estava desempenhando, talvez, o papel de terceiro nesta relação.

Daniela, no entanto, fez um pedido dirigido a mim de que a tirasse deste gozo desenfreado com a màe, o que apareceu claramente num desenho que fez numa de nossas primeiras entrevistas. Desenhou e contou a história de uma criança que estava caindo, pedindo socorro, mas no solo estava eu dizendo: "eu me chamo Renata, eu te salvo". Um trabalho analítico, então, foi empreendido com esta criança, dentro da instituição médica. Alguns sintomas sofreram deslocamentos logo nos primeiros meses de trabalho, liberando de certa forma o corpo deste sofrimento que entào podia ser falado.

\section{CONCLUSÃO}

Apesar de os discursos médico e analítico serem "discursos que se cruzam às vezes em torno dos mesmos sintomas, mas nào se articulam" (Clavreul, 1983), fica clara a importância da presença da psicanálise na instituição médica. Ela caminha no sentido contrário ao da medicina, na direção do resgate da subjetividade, da instauraçao do particular contra o ideal, com a funçào de nào permitir que o discurso vigente se cristalize e se torne totalitário. 


\section{REFERENNCIAS BIBLIOGRAFICAS}

ClaVreul, J.(1983) A Ordem Médica. Sào Paulo, Brasiliense.

DIAZ, R.F.(1993) "Para quê o psicanalista trabalha em um hospital". In Psicanálise e Cultura.

FOUlCaUlT, M.(1979) Microfisica do Poder. Rio de Janeiro, Graal.

LACAN, J.(1986) "Duas notas sobre a Criança". In Ornicar, publicaçào do Campo Freudiano, no. 37.

LAURENT, E. "El Psicoanalisis com los Niños". Como se Analiza Hoy? Buenos Aires, Manantial.

MATET, J. (1993) O sintoma é o que muitas pessoas têm de mais real. In: MILLER, G. (org.) Lacan, Rio de Janeiro, Jorge Zahar.

SILVESTRE, M. (1982) Qu'aus nous retenu de l'enseignement de Lacan dans notre pratique de psychanaliste d'enfants. Bruxelas. École de la Cause Freudienne. 